\title{
Measurements of the Attenuation by Means of the Scattered Light of Planar Waveguide Structure, Basing on the Polymer SU8 on a Substrate of Sodium-Calcium Glass
}

\begin{abstract}
K. Gut and D. Nabaglo
Department of Optoelectronics, Silesian University of Technology, Krzywoustego 2, 44-100 Gliwice, Poland

The paper presents the results of investigations concerning the measurement of the attenuation of planar waveguide structures obtained by means of the photopolymerization of the polymer SU8. The applied substrate was sodium-calcium glass. Attenuation is one of the fundamental parameters of optical waveguide, the knowledge of which is of crucial importance in the construction of various kinds of optical sensors. A method of its measurement has been presented, consisting in the recording of the intensity of scattered light making use of CCD camera. The paper deals also with the generation of planar polymer waveguide, taking into account problems connected with the adhesion to glass substrates.
\end{abstract}

PACS numbers: 42.25.Hz, 42.25.-p, 42.70.-a, 42.82.-m, 42.82.Et, 68.35.Ct

\section{Introduction}

For the purpose of constructing optical planar sensors various techniques are applied, e.g. ion exchange, plasma-enhanced chemical vapour deposition (PECVD) and spin coating in case of polymer waveguides [1-5].

SU8 is a polymer based on epoxy resin, developed in 1989 by IBM. Thanks to its properties it is now one of the most attractive materials used in the optical planar technology. SU8 is rather cheap and displays a high thermal and chemical stability as well as good resistance to mechanical damages and unusual transparency [6]. The wide range of products are ready for use, offered by the manufacturers of SU8 (MicroChem and Gersteltec Sari). In the course of one technological process layers can be obtained with a thickness of $1 \mu \mathrm{m}$ up to $2 \mathrm{~mm}$ [6].

Such good properties of polymer SU8 are due to its unique structure, shown in Fig. 1. The chief component is here epoxy resin, called EPON $\AA$, consisting of SU monomers and responsible for its mechanical properties and adhesion to the substrate. Another, also very important component is the photoinitiatior, viz. the Lewis acid, responsible for the initiation of the cross-linking, in the course of which an epoxy ring is opened [6]. The last component is a solvent, which is indispensable for warranting the adequate viscosity of the mixture.

So far SU8 has been applied mainly in the technologies MEMS and MOEMS, being a highly resistant and very sensitive photoresist processes involving a selective plasma digestion, but also in photolithography [7]. Because of its very good optical properties it is utilized in the production of optical sensors operating in the interferometer system $[7,8]$.

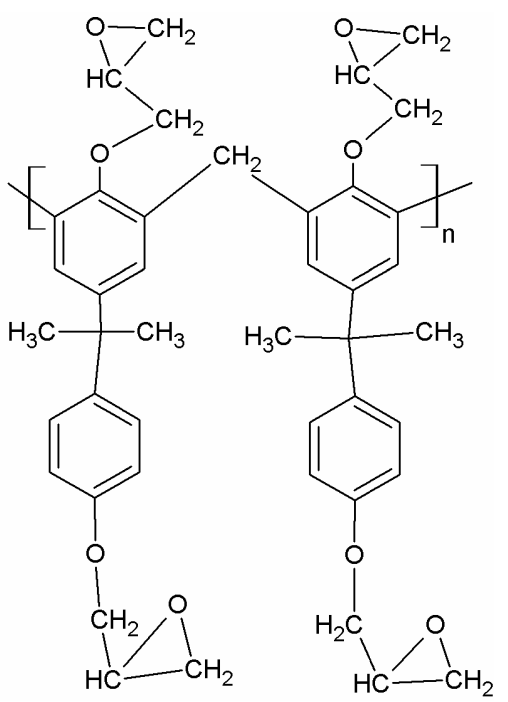

Fig. 1. Structure of the chain of the polymer SU8.

\section{Fabrication}

For the purpose of investigations a series of planar waveguide structures was prepared for the SU8 polymer of varying thickness. As a substrate sodium-calcium glass plates were used, previously washed and rinsed in nitric acid, acetic acid and ammonia liquor. The polymer SU8 is characterized by a weak adhesion to glass substrates [8]. Therefore, in order to avoid damages of the structure in the course of depositing the polymer the entire procedure of washing was accomplished in a laminar 
cell with air filtration, holding it for 5 min at a temperature of $130^{\circ} \mathrm{C}$. Upon the substrate SU8 was deposited by spin coating in a centrifuge (of the firm Rein Raum Technik Lanz), specially adapted for this purpose. The proper amount of SU8 was batched by means of an automatic feeder with its nozzle directed towards the immovable substrate mounted in the centrifuge. The thickness of the layers depended on the velocity of gyration of the centrifuge (Fig. 2).

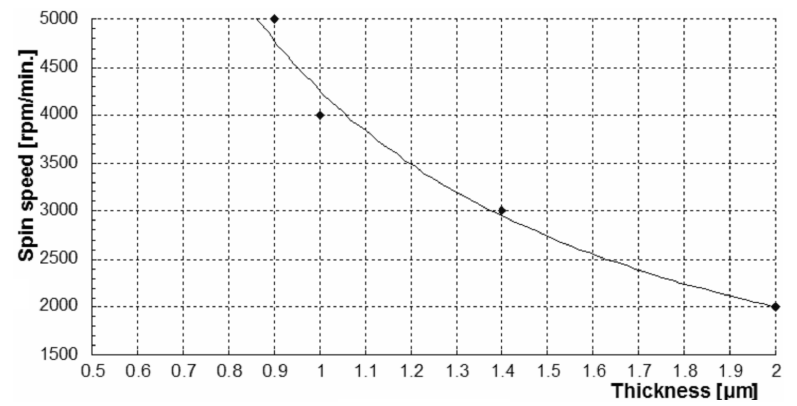

Fig. 2. Spin curve for SU8 GM1040 polymer.

In order to improve the homogeneity of the coating, each plate was, after the deposition of SU8, cooled down for five minutes to room temperature (relax time). Next, each structure was subjected to initial/preliminary soft baking on a hot plate provided with a microprocessing programmer. At this stage, the controlling of the temperature is of crucial importance for the whole process, and just therefore its precise measurement is indispensable. The profile of temperature changes both during the soft baking and in the course of heating after the exposure can be seen in Fig. 3 .

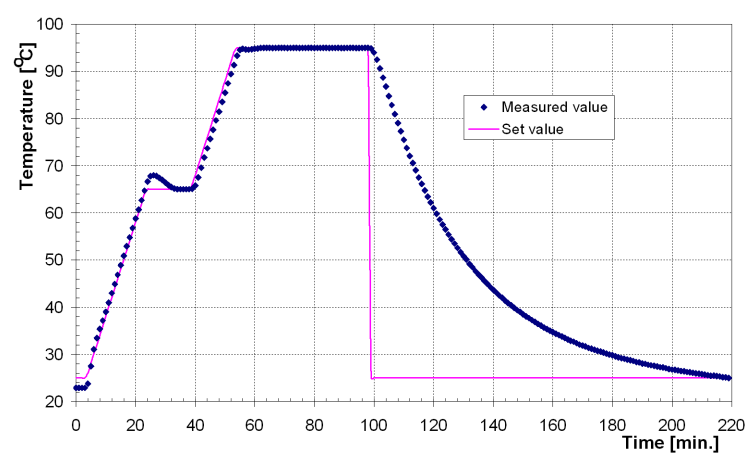

Fig. 3. Heating profile for pre-baking and post-exposure baking.

TABLE I

Technological conditions of deposition of SU8 waveguide layers.

\begin{tabular}{|c|c|c|c|c|c|c|}
\hline $\begin{array}{l}\text { Spin speed } \\
{[\mathrm{rpm} / \mathrm{min}]}\end{array}$ & Pre-baking & $\begin{array}{c}\begin{array}{c}\text { Relax time } \\
\text { [min] }\end{array} \\
\end{array}$ & $\begin{array}{c}\text { Exposure } \\
\text { time [s] }\end{array}$ & $\begin{array}{c}\mathrm{UV} \text { dose } \\
{\left[\mathrm{mJ} / \mathrm{cm}^{2}\right]}\end{array}$ & $\begin{array}{c}\text { Post-exposure } \\
\text { baking }\end{array}$ & $\begin{array}{c}\text { Developing } \\
\text { time }[\mathrm{s}]\end{array}$ \\
\hline 2000 & $\begin{array}{l}25^{\circ} \mathrm{C}-65^{\circ} \mathrm{C} / 20 \mathrm{~min}, \\
65^{\circ} \mathrm{C} / 6 \mathrm{~min}, \\
65^{\circ} \mathrm{C}-95^{\circ} \mathrm{C} / 15 \mathrm{~min}, \\
95^{\circ} \mathrm{C}-40 \min \end{array}$ & 5 & 42 & 235 & $\begin{array}{l}25^{\circ} \mathrm{C}-65^{\circ} \mathrm{C} / 20 \mathrm{~min}, \\
65^{\circ} \mathrm{C} / 6 \min , \\
65^{\circ} \mathrm{C}-95^{\circ} \mathrm{C} / 15 \min , \\
95^{\circ} \mathrm{C}-22 \min \end{array}$ & 35 \\
\hline 3000 & $\begin{array}{l}25^{\circ} \mathrm{C}-65^{\circ} \mathrm{C} / 20 \mathrm{~min}, \\
65^{\circ} \mathrm{C} / 6 \mathrm{~min}, \\
65^{\circ} \mathrm{C}-95^{\circ} \mathrm{C} / 15 \mathrm{~min}, \\
95^{\circ} \mathrm{C}-40 \min \end{array}$ & 5 & 36 & 202 & $\begin{array}{l}25^{\circ} \mathrm{C}-65^{\circ} \mathrm{C} / 20 \text { min } \\
65^{\circ} \mathrm{C} / 6 \min , \\
65^{\circ} \mathrm{C}-95^{\circ} \mathrm{C} / 15 \min , \\
95^{\circ} \mathrm{C}-22 \min \end{array}$ & 30 \\
\hline 4000 & $\begin{array}{l}25^{\circ} \mathrm{C}-65^{\circ} \mathrm{C} / 20 \mathrm{~min}, \\
65^{\circ} \mathrm{C} / 6 \mathrm{~min}, \\
65^{\circ} \mathrm{C}-95^{\circ} \mathrm{C} / 15 \min , \\
95^{\circ} \mathrm{C}-40 \mathrm{~min} \\
\end{array}$ & 5 & 32 & 180 & $\begin{array}{l}25^{\circ} \mathrm{C}-65^{\circ} \mathrm{C} / 20 \min , \\
65^{\circ} \mathrm{C} / 6 \min , \\
65^{\circ} \mathrm{C}-95^{\circ} \mathrm{C} / 15 \min , \\
95^{\circ} \mathrm{C}-22 \min \\
\end{array}$ & 27 \\
\hline 5000 & $\begin{array}{l}25^{\circ} \mathrm{C}-65^{\circ} \mathrm{C} / 20 \mathrm{~min}, \\
65^{\circ} \mathrm{C} / 6 \mathrm{~min}, \\
65^{\circ} \mathrm{C}-95^{\circ} \mathrm{C} / 15 \mathrm{~min}, \\
95^{\circ} \mathrm{C}-40 \mathrm{~min}\end{array}$ & 5 & 28 & 157 & $\begin{array}{l}25^{\circ} \mathrm{C}-65^{\circ} \mathrm{C} / 20 \mathrm{~min}, \\
65^{\circ} \mathrm{C} / 6 \mathrm{~min}, \\
65^{\circ} \mathrm{C}-95^{\circ} \mathrm{C} / 15 \mathrm{~min}, \\
95^{\circ} \mathrm{C}-22 \mathrm{~min}\end{array}$ & 25 \\
\hline
\end{tabular}

Each structure, irrespective of the thickness of the waveguide SU8 layer, was preheated from room temperature to $65^{\circ} \mathrm{C}$ with a surplus of $2^{\circ} \mathrm{C}$ [8], after which the temperature of $65^{\circ} \mathrm{C}$ was maintained for $10 \mathrm{~min}$. The following step was the heating up from $65^{\circ} \mathrm{C}$ to $95^{\circ} \mathrm{C}$ with a surplus of $2^{\circ} \mathrm{C} / \mathrm{min}$, whose latest temperature was maintained for $60 \mathrm{~min}$.

After the structure had cooled down to about $30^{\circ} \mathrm{C}$, its exposure was started. For this purpose an irradiator MJB3 produced by the firm Karl Suss was used. The 
batching of UV radiation by means of a mercury discharge lamp (OSRAM HBO $250 \mathrm{~W}$ ) was adjusted individually for each thickness of the SU8 layer. The parameters of irradiation have been gathered in Table I. The irradiation was followed by post-exposure baking, similarly as in the case of preliminary soft baking.

The final stage of generation was the development of the structure by means of the developer PGME [8]. The time of the development can also be gathered from Table I. After their development the structure was washed with isopropanol and dried at room temperature.

\section{Measurement of the attenuation applying the method of recording the intensity of scattered light}

This method is absolutely reliable, non-destructive and fast in its execution. Concerning this method it is assumed that the intensity of scattered light is proportional to the intensity of light in the waveguide. Such an assumption permits to determine the attenuation of the waveguide, and thus also to estimate how much of the entire power rating introduced into the waveguide gets lost due to absorption and dissipation.

Scattered light can be observed on the upper surface of the waveguide as visible radiation, its direction coinciding with the direction of the light introduced into the waveguide. The dependence of the intensity of the scattered light on the length of the way of propagation is expressed by the following relation [9]:

$$
I_{\mathrm{s}}=I_{0} \mathrm{e}^{-\alpha x},
$$

where $x$ - path of propagation, $I_{0}$ — power rating introduced into the waveguide at the point $x=0, \alpha$ - linear absorption coefficient $[1 / \mathrm{cm}]$.

By means of the relation (1) the attenuation coefficient can be determined as the directivity index of the straight line of the linear matching function $I_{\mathrm{S}}=f(x)$. Practically the value of attenuation coefficient $\alpha$ is expressed in the logarithmic scale, i.e. in $\mathrm{dB} / \mathrm{cm}$. This can be achieved by a conversion of the scale [10]:

$$
\ln I_{\mathrm{s}}=\ln I_{0}-\alpha x \Leftrightarrow 10 \cdot \log I_{\mathrm{s}}=b-\alpha_{\mathrm{dB}} x \text {. }
$$

The intensity of scattered light was recorded by means of CCD camera, provided with an optical system which permits to focus on the surface of the waveguide. The obtained images were analyzed in compliance with the relation (2), and the resulting value of the attenuation coefficient $\alpha_{\mathrm{dB}}$ was assessed to be the value of the coefficient of straight line matched to the function $f(x)=10 \log I_{\mathrm{S}}$. This test stand is shown in Fig. 4. It is equipped with grip holding the waveguide, a CCD camera and a computer with the dedicated software. The holder of the waveguide is provided with a manipulator which permits to adjust the position of the structure in relation to the camera. In the arm of the holder there is a laser as well as a diaphragm. The CCD camera is mounted above the upper plane of the waveguide. It possesses an optical system with an adjustable focal distance. It is of extreme importance that the camera is equipped with an adequate

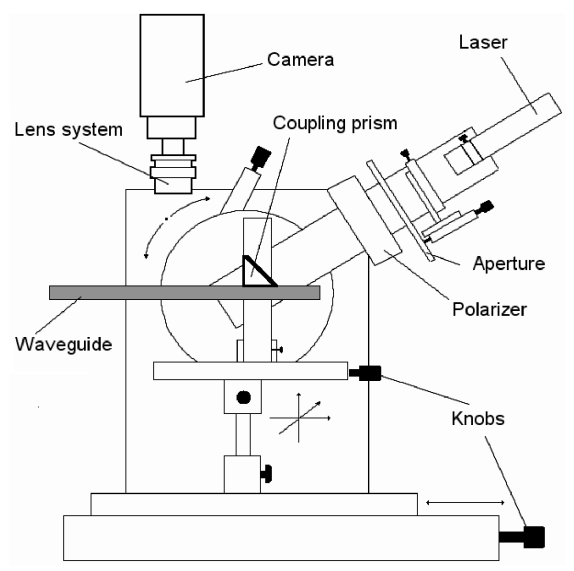

Fig. 4. Experimental setup [10].

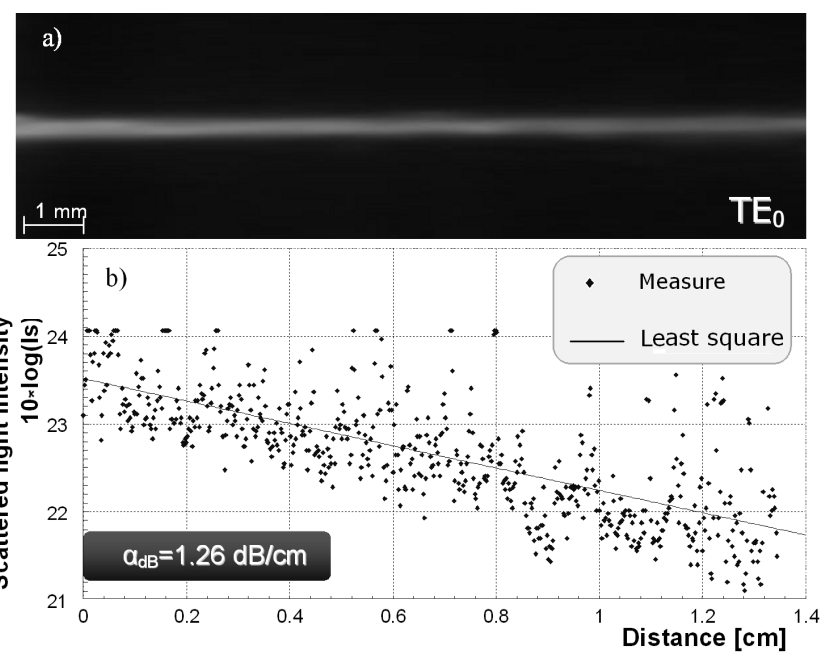

Fig. 5. 2D image captured by the CCD camera; (b) logarithmic dependence of the intensity of scattered light. Analyzed images of excited mode ( $\mathrm{TE}_{0}$ mode).
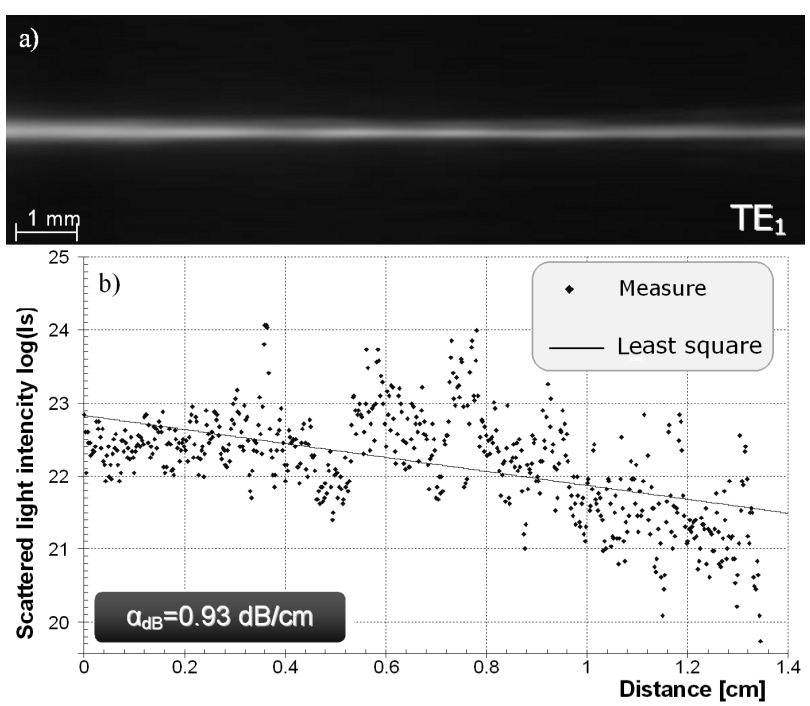

Fig. 6. The same as for Fig. 5, but for $\mathrm{TE}_{1}$ mode. 

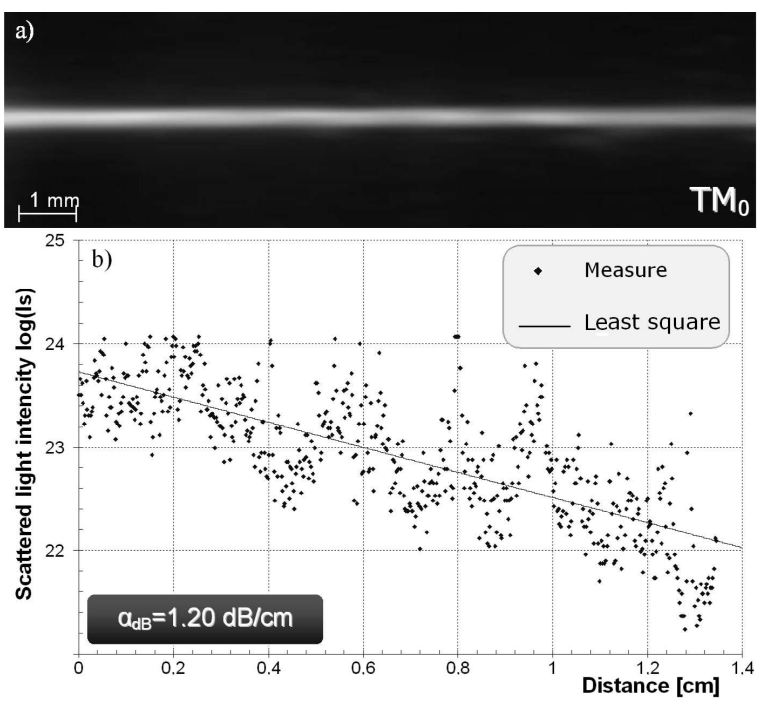

Fig. 7. The same as for Fig. 5, but for $\mathrm{TM}_{0}$ mode.
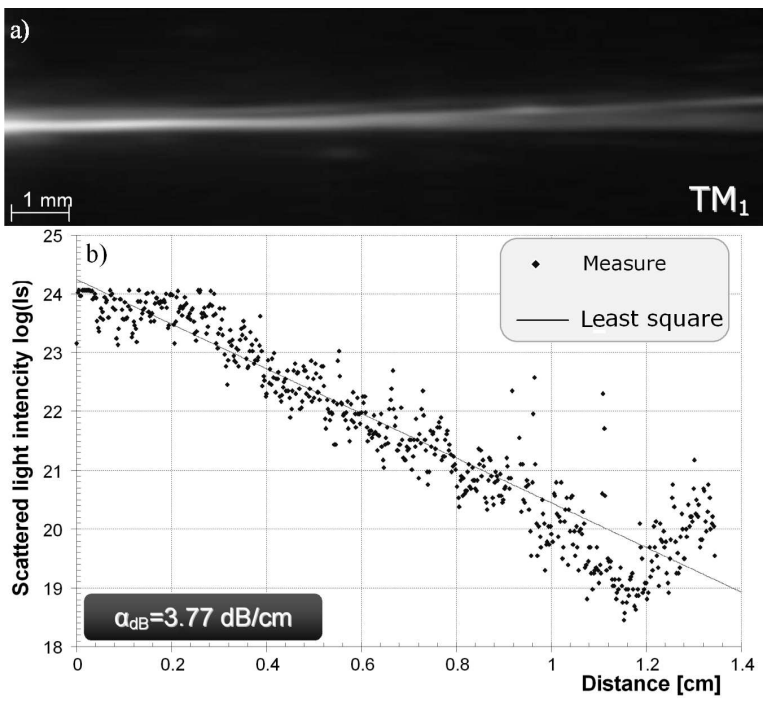

Fig. 8. The same as for Fig. 5, but for $\mathrm{TM}_{1}$ mode.

CCD transducer with linear sensitivity characteristics in the given range of wavelength in which the investigations are being run [10].

For the purpose of introducing light into waveguide a prism coupler was applied, placed inside the waveguide holder. The choice of proper polarization was accomplished by the proper rotation of the polarizer. The image was detected by means of a black-and-white camera GKB(CB23803SA 1/3" IR BW CCD) and the obtained images were gathered in form of a Bitmap, making use of the programme Dscaler.

\section{Results of the investigations}

The measurements concerned the polarizations TE and TM. For each of them subsequently modes of the zero and first order were recorded. The measurements were carried out for the wavelength of light of $635 \mathrm{~nm}$. The results of these measurements have been gathered in Table II.

\section{TABLE II}

Coefficients of mode attenuations.

\begin{tabular}{c|c|c}
\hline \hline Mode & $\alpha[1 / \mathrm{cm}]$ & $\alpha_{\mathrm{dB}}[\mathrm{dB} / \mathrm{cm}]$ \\
\hline $\mathrm{TE}_{0}$ & 0.29 & 1.26 \\
$\mathrm{TE}_{1}$ & 0.21 & 0.93 \\
$\mathrm{TM}_{0}$ & 0.28 & 1.20 \\
$\mathrm{TM}_{1}$ & 0.87 & 3.77
\end{tabular}

The following diagrams (Figs. 5-8) present the obtained results graphically. The thickness of the investigated waveguide amounted to $1.4 \mu \mathrm{m}$.

\section{Conclusion}

The presented method of measuring the attenuation of optical waveguide is simple and briefly realizable. The accuracy of the tested waveguides is conditioned first of all by the adequate CCD camera. This method is suitable for investigations of structures with a comparatively large optical attenuation coefficient, but less suitable in the cases of optic systems with rather low attenuation coefficients.

Experiments with the generation of planar waveguides on a glass substrate revealed problems with the adhesion of SU8 to the substrate. The adhesion can be improved by proper washing and baking previous to the deposition of the polymer.

The results of the presented investigation have proved that the attenuation of light in the generated structures is rather small therefore, feasible when such a waveguide is applied for the purpose of constructing optical sensors [11-17].

\section{Acknowledgments}

This work has been supported by the Polish Ministry of Science and Higher Education within the grant No. R01 03901.

\section{References}

[1] T. Pustelny, Physical and Technical Aspects of Optoelectronic Sensors, Publisher of SUT, Gliwice 2005, p. 86 .

[2] A. Sabac, C. Gorecki, M. Jozwik, L. Nieradko, C. Meunier, K. Gut, J. Eur. Opt. Soc.-Rapid 2, 07026 (2007).

[3] K. Gut, Acta Phys. Pol. A 114, A-121 (2008).

[4] K. Gut, J. Phys. IV 137, 91 (2006).

[5] K. Gut, J. Phys. IV 129, 109 (2005). 
[6] L. Akesso, SU8 Technical Datasheet, Gersteltec Sarl 2005.

[7] M. Bednorz, M. Urbańczyk, T. Pustelny, A. Piotrowska, E. Papis, Z. Sidor, E. Kamińska, Mol. Quant. Acoust. 27, 31 (2006).

[8] B. Beche, N. Pelletier, E. Gaviot, J. Zyss, Opt. Commun. 230, 91 (2004).

[9] F. Wang, F. Liu, G. Chang, Opt. Eng. 47, 024602 (2008).

[10] K. Gut, K. Nowak, Eur. Phys. J.-Spec. Top. 154, 89 (2008).

[11] K. Golaszewska, E. Kaminska, T. Pustelny, P. Struk, T. Piotrowski, A. Piotrowska, M. Ekielski, R. Kruszka, M. Wzorek, M. Borysewicz, I. Pasternak, K. Gut, Acta Phys. Pol. A 114, A-221 (2008).

[12] T. Pustelny, E. Maciak, Z. Opilski, A. Piotrowska, E. Papis, K. Gołaszewska, Europ. Phys. J.-Spec. Top. 154, 155 (2008).
[13] T. Pustelny, E. Maciak, Z. Opilski, M. Bednorz, Opt. Appl. 37, 187 (2007).

[14] K. Gut, M. Nowak, T. Pustelny, Mol. Quant. Acoust. 28, 101 (2007).

[15] W. Jakubik, E. Maciak, T. Pustelny, A. Stolarczyk, M. Urbanczyk, Mol. Quant. Acoust. 28, 125 (2007).

[16] B. Pustelny, T. Pustelny, Mol. Quant. Acoust. 28, 223 (2007).

[17] T. Pustelny, A. Opilski, B. Pustelny, Acta Phys. Pol. A 114, A-183 (2008). 